OPEN ACCESS

Edited by:

Ding Ding,

Fudan University, China

Reviewed by:

Chong Tin Chong Tan,

University of Malaya, Malaysia

Jing-Jane Tsai,

National Cheng Kung University

Hospital, Taiwan

Kheng Seang Lim,

University of Malaya, Malaysia

*Correspondence:

Dong Zhou

zhoudong66@yahoo.de

tThese authors have contributed equally to this work

Specialty section: This article was submitted to

Neuroepidemiology,

a section of the journal

Frontiers in Neurology

Received: 11 July 2018 Accepted: 01 October 2018 Published: 30 October 2018

Citation:

Chen J, Wu X, He Y, Li S, Deng Y, Chen J, Fang W, Zeren Z, Peng J, Li Y,

Mu J and Zhou D (2018) A

Retrospective Analysis of the Clinical Features of Inpatients With Epilepsy in the Ganzi Tibetan Autonomous

Prefecture. Front. Neurol. 9:891. doi: 10.3389/fneur.2018.00891

\section{A Retrospective Analysis of the Clinical Features of Inpatients With Epilepsy in the Ganzi Tibetan Autonomous Prefecture}

Jiani Chen ${ }^{1+}$, Xintong $\mathrm{Wu}^{1 \dagger}$, Yongqiao $\mathrm{He}^{2}$, Sisi $\mathrm{Li}^{1}$, Yongyi Deng ${ }^{2}$, Jie Chen ${ }^{2}$, Wenyu Fang ${ }^{2}$, Zhamu Zeren ${ }^{2}$, Jianmei Peng ${ }^{2}$, Yingjuan $\mathrm{Li}^{2}$, Jie $\mathrm{Mu}^{1}$ and Dong Zhou ${ }^{1 *}$

${ }^{1}$ Department of Neurology, West China Hospital, Sichuan University, Chengdu, China, ${ }^{2}$ Department of Neurology, Ganzi

Tibetan Autonomous Prefecture People's Hospital, Kangding, China

Background: There is limited detailed clinical information for patients with epilepsy in Tibet. This study sought to provide data about the clinical features of epilepsy in the Ganzi Tibetan Autonomous Prefecture to improve strategies for epilepsy prevention and management in this region.

Methods: We reviewed the clinical record of patients with epilepsy in the Neurology Department, Ganzi Tibetan Autonomous Prefecture People's Hospital and compared the clinical features and compared it with control, from West China Hospital in Chengdu.

Results: This retrospective study included 165 patients with epilepsy admitted between January 2015 and February 2018. Majority of patients (97\%) in this study had active epilepsy; $28.5 \%$ had generalized onset seizures and $68.5 \%$ had focal onset seizures. Fifty-four patients had received anti-epileptic drug (AED) treatment prior to hospitalization, however, 38 (70.4\%) patients took the medication irregularly. The leading etiology of this cohort was head trauma (20.6\%), followed by stroke (10.9\%), neurocysticercosis $(7.9 \%)$, brain hydatidosis (6.7\%) and tuberculous infection (5.5\%). Compared with in-patients in Chengdu, epilepsy in Ganzi was more frequently caused by infection (OR $=4.216,95 \%$ $\mathrm{Cl}, 2.124-8.367)$, including neurocysticercosis (OR $=29.301,95 \% \mathrm{Cl}, 1.727-497.167)$ and brain hydatidosis (OR $=24.637,95 \% \mathrm{Cl}, 1.439-421.670)$.

Conclusions: These data suggest that the control of cerebral infections, especially parasite infection, is essential for the prevention of epilepsy in the Ganzi Tibetan Autonomous Prefecture. Education of local primary doctors and patients about the literacy of epilepsy will enable better management of epilepsy in this population.

Keywords: cerebral infection, clinical features and atiology, epilepsy, Ganzi Tibetan Autonomous Prefecture, retrospective study 


\section{INTRODUCTION}

Epilepsy is one of the most common neurological disorders in the world that affects people of all nations and socioeconomic classes. The Tibetan area, which is on the Qinghai-Tibetan plateau, is $\sim 4,000 \mathrm{~m}$ above sea level. There are very few studies of epilepsy in this area $(1,2)$. A survey done in one of the counties in Tibet found that the lifetime prevalence of convulsive epilepsy was $\sim 2.5$ per 1,000 with a treatment gap of up to $97 \%$. No EEG or imaging data were available in this study (1). Another study summarized 180 cases of patients with epilepsy (PWE) and reported that the etiology was unknown in 145 cases $(80.6 \%)$ and no EEG or imaging data were available (2). Detailed clinical information, such as MRI and EEG results in the Tibet area, remains limited.

This study sought to provide data about the clinical features of epilepsy in the Ganzi Tibetan Autonomous Prefecture. Ganzi Tibetan Autonomous Prefecture is on the South-eastern edge of the Qinghai-Tibetan plateau, in the Western part of Sichuan Province. The average altitude is 3,500 meters above sea level. Tibetan is the primary ethnic group. With a population of one million, Ganzi Tibetan Autonomous Prefecture is the second largest inhabited region of Tibetan people in China. Many locals earn their living by farming or yak herding (3).

In this study, clinical records of patients admitted to Ganzi Tibetan Autonomous Prefecture People's Hospital and diagnosed with epilepsy were retrospectively reviewed. The study aimed at providing an updated information on the clinical features of epilepsy in the Tibetan area to help improve strategies for epilepsy prevention and management in this region.

\section{MATERIALS AND METHODS Study Location and Population}

The Ganzi Tibetan Autonomous Prefecture People's Hospital is in Kangding City, Sichuan province, the capital of the Ganzi Tibetan Autonomous Prefecture. It is the only hospital equipped with MRI and Video EEG in Ganzi. West China Hospital, a large tertiary referral center in West China, has been sending a neurologist to the Ganzi Tibetan Autonomous Prefecture People's Hospital every year since 2014 to live and work with the local neurologists.

\section{Study Design}

Patients with epilepsy that were admitted to the Neurology Department of Ganzi Tibetan Autonomous Prefecture People's Hospital, between January 2015 and February 2018, were retrospectively and consecutively included in this study. To explore the clinical features of inpatients with epilepsy in Ganzi, demographic and clinical data collected were compared with the data from West China Hospital in Chengdu (control group). Controls' data were retrieved from in-patient epilepsy database of West China Hospital in Chengdu City between June 2017 and February 2018. PWE in Ganzi were identified and matched for gender, age ( \pm 2 years) in the controls database. In cases where there were several matched controls, the one with early admission date would be included.
The following definitions were considered: epilepsy is defined according to the 2014 International League Against Epilepsy (ILAE) as two spontaneous seizures with one occurring within the last 6 months, or one seizure with an epileptiform discharge shown by EEG or an enduring relevant lesion shown by imaging $(4,5)$.

Status epilepticus (SE) is defined according to the 2015 ILAE as a condition resulting from the failure of the mechanisms responsible for seizure termination or initiation of mechanisms which lead to abnormally prolonged seizures. Convulsive SE is defined as more than $5 \mathrm{~min}$ of continuous seizure or two or more discrete seizures with incomplete recovery between them (6).

Patients were excluded if they reported symptomatic seizures occurring $<2$ weeks after the onset of acute cerebral insults and if they lived outside of the Ganzi Tibetan Autonomous Prefecture.

Controls were excluded if they reported symptomatic seizures occurring $<2$ weeks after the onset of acute cerebral insults.

\section{Socio-Demographic Status and Clinical Information}

Data were collated retrospectively using a structured data collection form by reviewing the medical charts. All patients recruited had been diagnosed with epilepsy by two neurologists, from both the Ganzi Tibetan Autonomous Prefecture People's Hospital and West China Hospital. Differences in opinion were resolved by consensus. Demographic information included gender, age, marriage status, living area, education, job, and ethnicity were collected.

Clinical information was collected from all patients and the control. This included: age at the seizure onset, seizure frequency, and AEDs. The results of EEG and MRI/CT scans were reviewed and recorded. The MRI prescribed was a $1.5-\mathrm{T}$ imaging system (Philips Achieva, Holland \& Sonata, Siemens, Germany). Most patients in our clinic underwent neuroimaging as part of routine checks. Local or generalized slow waves in the EEG recording were considered non-specific abnormalities, while local or generalized paroxysms of sharp waves, spike waves, sharp and slow waves, or spike and slow waves were considered epileptiform discharges. Epileptic seizures were classified according to ILAE 2017 classification as focal seizures (focal aware seizures, focal impaired awareness seizures, or focal to bilateral tonic-clonic seizures), generalized seizures (non-motor, other motor or tonic-clonic), and unknown (7). Etiology was defined as the presence of remote brain injury that causes seizure episodes (8). Diagnosis was typically established on the basis of clinical history, past medical records, and laboratory results, and was further confirmed by neuro imaging. Etiology was classified according to ILAE 2017 classification as structural, infectious, genetic, metabolic, immune, and unknown etiology (7, 9). Specific etiologies were also listed, including neurocysticercosis, brain hydatidosis, stroke, head trauma, cerebral tumor, hippocampal sclerosis, cortical dysplasia, unclear intracranial space-occupying lesions, and so on.

The study was approved by the West China Hospital clinical trial and biomedical ethics committee and the ethics committee of the Ganzi Tibetan Autonomous Prefecture People's Hospital. 


\section{Data Analysis}

Descriptive statistics of the patients and controls were conducted. Quantitative data were expressed as the mean $\pm \mathrm{SD}$. Qualitative data were summarized as proportions. A comparison of demographic and clinical data between the two groups was done using Student's $T$-tests/Mann Whitney $U$ test for continuous variables and Chi-squared tests for categorical variables, respectively.

IBM SPSS 23.0 was used to perform all analyses. All of the tests were two-tailed, and $p$-values $<0.05$ were considered to be statistically significant.

\section{RESULTS}

\section{Demographic Data of the Participants}

One hundred and sixty-seven PWE were admitted to the Neurology Department of the Ganzi Tibetan Autonomous Prefecture People's Hospital from January 2015 to February 2018. Out of these, two patients were excluded because they were travelers living outside the Ganzi Tibetan Autonomous Prefecture. Hence, 165 patients were included in the study.

Our patient population included $96(58.2 \%)$ men and 69 (41.8\%) women. Other demographic features are listed in Table 1. The mean patient age was $39.4 \pm 16.8$ years. Forty-one (24.8\%) patients lived in an urban location, and $124(75.2 \%)$ lived in a rural/pastoral location. Most patients were Tibetan $(n=128$, $77.6 \%)$ or Han Chinese $(n=34,20.6 \%)$. The number of illiterate patients was $104(63.0 \%)$, and $60.6 \%$ of the total patients were farmers.

A comparison of the demographic characteristics of the inpatients in Ganzi and gender and age-matched controls in Chengdu was done (Table 1). The comparison indicates that there were more patients in Ganzi who lived in rural/pasture areas compared to the controls ( 75.2 vs. $36.4 \%, p<0.001$ ) as well as lower education levels (the illiterate up to 63.0 vs. $1.2 \%, p<$ $0.001)$. There was also a significant difference in job groups ( $p$ $<0.001)$ and ethnic group distribution (77.6\% Tibetan in Ganzi patients, $p<0.001$ ). No differences were detected for the age, gender, and marital status.

\section{Clinical Features}

The mean age at the time of seizure onset was $34.5 \pm 18.0$ years. No significant difference was noted when this was compared with the data from the control group (Table 2). In addition, there were more patients newly diagnosed with epilepsy 104 (63.0\%) compared to the control group (63.0 vs. $33.3 \%, p<$ $0.001)$. The different seizure types were as follows: focal aware seizures $(n=5,3.0 \%)$; focal impaired awareness seizures $(n=12$, $7.3 \%)$; focal to bilateral tonic-clonic seizures $(n=96,58.2 \%)$; and generalized tonic-clonic seizures $(n=46,27.9 \%)$. Thirtythree (20\%) out of 165 patients were diagnosed with SE, while 2 (1.2\%) died following prolonged SE. No significant difference in seizure type fund between groups (focal/generalized/unknown, $p=0.087)$. Most (98.8\%) patients underwent an MRI or CT scan; abnormalities were noted in $102(61.8 \%)$ patients. These were more than those in the control group (61.8 vs. $38.2 \%, p<$ 0.001). EEG or video EEG was performed in 51 (30.9\%) patients.
TABLE 1 | Demographic features of PWEs in the neurology department of Ganzi people's hospital and control group from West China hospital.

\begin{tabular}{|c|c|c|c|}
\hline Variable & $\begin{array}{l}\text { PWEs in Ganzi } \\
N=165\end{array}$ & $\begin{array}{l}\text { Control group } \\
N=165\end{array}$ & $P$-value \\
\hline Gender, $n(\%)$ & - & - & 1.000 \\
\hline Female & 69 (41.8\%) & $69(41.8 \%)$ & - \\
\hline Male & 96 (58.2\%) & $96(58.2 \%)$ & - \\
\hline $\begin{array}{l}\text { Age (year, mean } \pm \\
\text { SD) }\end{array}$ & $\begin{array}{c}39.4 \pm \\
16.8\end{array}$ & $\begin{array}{c}40.0 \pm \\
17.0\end{array}$ & 0.721 \\
\hline Age group, $n(\%)$ & - & - & 0.996 \\
\hline$\leq 14$ years & $5(3.0 \%)$ & 5 (3.0\%) & - \\
\hline $15-44$ years & 99 (60.0\%) & 97 (58.8\%) & - \\
\hline $45-59$ years & 37 (22.5\%) & 38 (23.0\%) & - \\
\hline$\geq 60$ years & 24 (14.5\%) & 25 (15.2\%) & - \\
\hline Marriage, $n(\%)$ & - & - & 0.729 \\
\hline Married & $\begin{array}{c}109 \\
(66.1 \%)\end{array}$ & $\begin{array}{c}106 \\
(64.2 \%)\end{array}$ & - \\
\hline Single & 56 (33.9\%) & 59 (35.8\%) & - \\
\hline Living area, $n(\%)$ & - & - & $0.000^{\star}$ \\
\hline Urban & 41 (24.8\%) & $\begin{array}{c}105 \\
(63.6 \%)\end{array}$ & - \\
\hline Rural/pastoral & $\begin{array}{c}124 \\
(75.2 \%)\end{array}$ & 60 (36.4\%) & - \\
\hline $\begin{array}{l}\text { Education } \\
\text { status, } n(\%)\end{array}$ & - & - & $0.000^{\star}$ \\
\hline Illiterate & $\begin{array}{c}104 \\
(63.0 \%)\end{array}$ & $2(1.2 \%)$ & - \\
\hline $\begin{array}{l}\text { Primary } \\
\text { school and middle } \\
\text { school }\end{array}$ & 38 (23.0\%) & 77 (46.7\%) & - \\
\hline High school & $15(9.1 \%)$ & 37 (22.4\%) & - \\
\hline College & $8(4.8 \%)$ & 49 (29.7\%) & - \\
\hline Job, $n(\%)$ & - & - & $0.000^{\star}$ \\
\hline $\begin{array}{c}\text { Not } \\
\text { employed }^{b}\end{array}$ & $9(5.5 \%)$ & 41 (24.8\%) & - \\
\hline Student & 17 (10.3\%) & 26 (15.8\%) & - \\
\hline Farmer & $\begin{array}{c}100 \\
(60.6 \%)\end{array}$ & 30 (18.2\%) & - \\
\hline Employment & 21 (12.7\%) & 46 (27.8\%) & - \\
\hline Retirement & 7 (4.2\%) & $11(6.7 \%)$ & - \\
\hline Other & $11(6.7 \%)$ & $11(6.7 \%)$ & - \\
\hline $\begin{array}{l}\text { Ethnic Group, } n \\
(\%)\end{array}$ & - & - & $0.000^{\star a}$ \\
\hline Han & 34 (20.6\%) & $\begin{array}{c}158 \\
(95.8 \%)\end{array}$ & - \\
\hline Tibetan & $\begin{array}{c}128 \\
(77.6 \%)\end{array}$ & $5(3.0 \%)$ & - \\
\hline Yi & 3 (1.8\%) & $2(1.2 \%)$ & - \\
\hline
\end{tabular}

${ }^{*} P<0.05$.

${ }^{a}$ Fisher exact test.

${ }^{b}$ Including housewife.

These were less than those in the control group (30.9 vs. 91.5\%, $p<0.001)$. The results of the EEG studies revealed that 27 (52.9\%) and 19 (37.3\%) patients showed epileptiform discharge and normal EEG, respectively. 
TABLE 2 | Clinical features of PWEs in neurology department of Ganzi people's hospital and control group from West China hospital.

\begin{tabular}{|c|c|c|c|}
\hline Variable & $\begin{array}{l}\text { PWEs in Ganzi } \\
N=165\end{array}$ & $\begin{array}{l}\text { Control group } \\
N=165\end{array}$ & $P$-value \\
\hline $\begin{array}{l}\text { Age of onset (year, } \\
\text { mean } \pm S D \text { ) }\end{array}$ & $\begin{array}{c}34.5 \pm \\
18.0\end{array}$ & $\begin{array}{c}31.9 \pm \\
19.0\end{array}$ & 0.208 \\
\hline $\begin{array}{l}\text { Admitted for } \\
\text { status epilepticus, } \\
n(\%)\end{array}$ & 33 (20.0\%) & 17 (10.3\%) & $0.014^{\star}$ \\
\hline $\begin{array}{l}\text { Death after status } \\
\text { epilepticus }\end{array}$ & $2(6.1 \%)$ & $0(0 \%)$ & $0.517^{a}$ \\
\hline Newly diagnosis & $\begin{array}{c}104 \\
(63.0 \%)\end{array}$ & 55 (33.3\%) & $0.000^{\star}$ \\
\hline Seizure type, $n(\%)$ & - & - & $0.087^{\star b}$ \\
\hline $\begin{array}{l}\text { Generalized } \\
\text { onset }\end{array}$ & 47 (28.5\%) & $66(40 \%)$ & - \\
\hline Tonic-clonic & 46 (27.9\%) & 65 (39.4\%) & - \\
\hline Nonmotor & $1(0.6 \%)$ & $1(0.6 \%)$ & - \\
\hline Focal onset & $\begin{array}{c}113 \\
(68.5 \%)\end{array}$ & 95 (57.6\%) & - \\
\hline $\begin{array}{l}\text { Impaired } \\
\text { awareness }\end{array}$ & $12(7.3 \%)$ & 32 (19.4\%) & - \\
\hline Aware & $5(3.0 \%)$ & $7(4.2 \%)$ & - \\
\hline $\begin{array}{l}\text { Focal to } \\
\text { bilateral } \\
\text { tonic-clonic }\end{array}$ & 96 (58.2\%) & 56 (33.9\%) & - \\
\hline Unknown onset & 5 (3.0\%) & 4 (2.4\%) & - \\
\hline EEG, $n(\%)$ & 51 (30.9\%) & $\begin{array}{c}151 \\
(91.5 \%)\end{array}$ & $0.001^{\star}$ \\
\hline Normal & 19 (37.3\%) & 87 (57.6\%) & - \\
\hline $\begin{array}{l}\text { Non-specific } \\
\text { abnormality }\end{array}$ & $5(9.8 \%)$ & 26 (17.2\%) & - \\
\hline $\begin{array}{l}\text { Epileptiform } \\
\text { discharge }\end{array}$ & 27 (52.9\%) & 38 (25.2\%) & - \\
\hline $\begin{array}{l}\text { MRI/CT scan, } n \\
\text { (\%) }\end{array}$ & - & - & $0.000^{\star}$ \\
\hline Abnormal & $\begin{array}{c}102 \\
(61.8 \%)\end{array}$ & $63(38.2 \%)$ & - \\
\hline Normal & 61 (37.0\%) & $\begin{array}{c}100 \\
(60.6 \%)\end{array}$ & - \\
\hline $\begin{array}{l}\text { Anti-epileptic } \\
\text { drugs at the time } \\
\text { of discharge, } n(\%)\end{array}$ & - & - & $0.000^{\star}$ \\
\hline No treatment & 18 (10.9\%) & 24 (14.5\%) & - \\
\hline Mono-therapy & $\begin{array}{c}129 \\
(78.2 \%)\end{array}$ & 90 (54.5\%) & - \\
\hline Poly-therapy & 18 (10.9\%) & 51 (31.0\%) & - \\
\hline
\end{tabular}

${ }^{*} P<0.05$.

${ }^{a}$ Haldane-Anscombe correction.

${ }^{b}$ Fisher exact test.

The data collected also revealed that 61 (36.9\%) patients had been diagnosed with epilepsy prior to hospitalization with 54 of these patients receiving prescriptions for AEDs. However, $38(70.4 \%)$ patients reported irregular use of medication, significantly higher than the control group (70.4 vs. 22.5\%, $p<0.001)$. Moreover, 5 cases of SE were precipitated by nonadherence to the medication regime. The mean duration of status epilepticus before admission was $15.5 \mathrm{~h}$ (range $0.5-48$ ). Most patients in this study (97.0\%) had active epilepsy (seizure free $<1$ year) (10).

\section{Etiology}

The etiological factors of epilepsy in Ganzi are summarized in Table 3. With the ILAE 2017 classification, 39.4\% had a structural etiology, $24.8 \%$ had an infectious etiology, $4.8 \%$ had a presumed genetic cause, and $29.7 \%$ was classified as unknown.

As to specific causes of epilepsy, the leading cause was head trauma ( $n=34,20.6 \%)$, followed by stroke ( $n=18,10.9 \%)$, neurocysticercosis $(n=13,7.9 \%)$, brain hydatidosis $(n=11$, $6.7 \%)$ and tuberculous infection $(n=9,5.5 \%)$. Other etiologies included presumed genetic cause $(n=8,4.8 \%)$, viral infection $(n=6,3.6 \%)$ and unclear intracranial space-occupying lesions $(n=5,3.0 \%)$. Less common etiologies included tumor $(n=3$, $1.8 \%)$, cortical dysplasia $(n=4,2.4 \%)$, and hippocampal sclerosis $(n=1,0.6 \%)$.

When compared with the control group, PWEs in Ganzi significantly had more frequent infectious etiology $(\mathrm{OR}=4.216$, 95\% CI, 2.124-8.367). And epilepsy in Ganzi was caused more frequently by head trauma $(\mathrm{OR}=1.994,95 \% \mathrm{CI}, 1.084-$ 3.666), neurocysticercosis ( $\mathrm{OR}=29.301,95 \% \mathrm{CI}, 1.727-497.167)$ and brain hydatidosis (OR $=24.637,95 \% \mathrm{CI}, 1.439-421.670)$. Epilepsy in Ganzi was less frequently caused by hippocampus sclerosis $(\mathrm{OR}=0.094,95 \% \mathrm{CI}, 0.012-0.747)$. The percentage of patients with unknown etiology in Ganzi was lower compared with the control group $(\mathrm{OR}=0.532,95 \% \mathrm{CI}, 0.338-0.838)$.

\section{DISCUSSION}

The present study focused on the clinical features of epilepsy in the Ganzi Tibetan Autonomous Prefecture, which is currently under-studied. The aim is to obtain clinical information that would lead to improved strategies in prevention, management, education, and treatment of epilepsy in this region.

\section{Status Epilepticus}

Thirty-three PWE who were admitted to the hospital had SE. Two of them $(6.1 \%)$ died in the hospital. The reported overall mortality is $\sim 20 \%$ in the first month after SE (11). However, in SE without provoked factors, the reported rate of death is $\sim 10 \%$ $(11,12)$. In the current study, we excluded acute symptomatic cases from our cohort. For the two fatalities recorded, it was noted that the SE lasted for more than 1 day before proper treatment was initiated. In addition, some people living in the remote county of the Ganzi Autonomous Tibetan Prefecture would require 2 days drive to reach the People's Hospital. This may have been the reason for delayed diagnosis and treatment. The mean duration of SE before admission was $15.5 \mathrm{~h}$ (range $0.5-$ 48). It is therefore important that primary hospital physicians have to provide early diagnosis and control of SE. A survey done on attitudes and management practices of epilepsy among 100 primary practitioners in Ganzi, 2017, revealed that 49\% did not know how to treat SE (unpublished data). It is therefore important to train primary practitioners and equip them with skills to control these cases. 
TABLE 3 | General etiologic features of the epilepsy patients.

\begin{tabular}{|c|c|c|c|}
\hline $\begin{array}{l}\text { Etiology } \\
\text { classification }\end{array}$ & $\begin{array}{l}\text { PWEs in Ganzi } \\
N=165\end{array}$ & $\begin{array}{l}\text { Control group } \\
N=165\end{array}$ & OR $(95 \% \mathrm{Cl})$ \\
\hline Infectious & $41(24.8 \%)$ & $12(7.3 \%)$ & $\begin{array}{c}4.216 \\
(2.124-8.367)^{\star}\end{array}$ \\
\hline Neurocysticercosis & 13 (7.9\%) & $0(0.0 \%)$ & $\begin{array}{c}29.301 \\
(1.727-497.167)^{\star \star}\end{array}$ \\
\hline Brain hydatidosis & $11(6.7 \%)$ & $0(0.0 \%)$ & $\begin{array}{c}24.637 \\
(1.439-421.670)^{\star \star}\end{array}$ \\
\hline Tuberculous & 9 (5.5\%) & $3(1.8 \%)$ & $\begin{array}{c}3.115 \\
(0.828-11.721)\end{array}$ \\
\hline Viral infection & $6(3.6 \%)$ & $8(4.8 \%)$ & $\begin{array}{c}0.740 \\
(0.251-2.183)\end{array}$ \\
\hline Brain abcess & $2(1.2 \%)$ & $1(0.6 \%)$ & $\begin{array}{c}1.974 \\
(0.177-22.001)\end{array}$ \\
\hline Structural & 65 (39.4\%) & 60 (36.4\%) & $\begin{array}{c}1.137 \\
(0.728-1.775)\end{array}$ \\
\hline Head trauma & $34(20.6 \%)$ & 19 (11.5\%) & $\begin{array}{c}1.994 \\
(1.084-3.666)^{\star}\end{array}$ \\
\hline Stroke & 18 (10.9\%) & 11 (6.7\%) & $\begin{array}{c}1.714 \\
(0.783-3.752)\end{array}$ \\
\hline Ischemic & $11(6.7 \%)$ & $5(3.0 \%)$ & $\begin{array}{c}2.285 \\
(0.776-6.731)\end{array}$ \\
\hline Hemorrhage & 7 (4.2\%) & $6(3.6 \%)$ & $\begin{array}{c}1.174 \\
(0.386-3.571)\end{array}$ \\
\hline Cerebral tumor & $3(1.8 \%)$ & $6(3.6 \%)$ & $\begin{array}{c}0.490 \\
(0.120-1.996)\end{array}$ \\
\hline $\begin{array}{l}\text { Hippocampus } \\
\text { sclerosis }\end{array}$ & $1(0.6 \%)$ & 10 (6.0\%) & $\begin{array}{c}0.094 \\
(0.012-0.747)^{\star}\end{array}$ \\
\hline Cortical dysplasia & $4(2.4 \%)$ & $8(4.8 \%)$ & $\begin{array}{c}0.487 \\
(0.143-1.651)\end{array}$ \\
\hline $\begin{array}{l}\text { Unclear } \\
\text { intracranial } \\
\text { space-occupying } \\
\text { lesions }\end{array}$ & 5 (3.0\%) & $3(1.8 \%)$ & $\begin{array}{c}1.687 \\
(0.396-7.179)\end{array}$ \\
\hline $\begin{array}{l}\text { Other structural } \\
\text { changes }\end{array}$ & $0(0.0 \%)$ & $3(1.8 \%)$ & $\begin{array}{c}0.143 \\
(0.007-2.737)^{\mathrm{a}}\end{array}$ \\
\hline Metabolic & 0 (0.0\%) & $0(0.0 \%)$ & $\begin{array}{c}1.000 \\
(0.019-50.699)^{\mathrm{a}}\end{array}$ \\
\hline Immune ${ }^{b}$ & $2(1.2 \%)$ & $3(1.8 \%)$ & $\begin{array}{c}0.662 \\
(0.109-4.018)\end{array}$ \\
\hline $\begin{array}{l}\text { Presumed genetic } \\
\text { cause }^{c}\end{array}$ & $8(4.8 \%)$ & 17 (10.3\%) & $\begin{array}{c}0.443 \\
(0.186-1.058)\end{array}$ \\
\hline Unknown & 49 (29.7\%) & 73 (44.2\%) & $\begin{array}{c}0.532 \\
(0.338-0.838)^{\star}\end{array}$ \\
\hline
\end{tabular}

" $P<0.05$.

${ }^{a}$ Haldane-Anscombe correction.

${ }^{b}$ Autoimmune encephalitis.

cIncluded Genetic Generalized Epilepsies.

\section{AED, Seizure Control and Medication Compliance}

The findings of this study indicate that $63.0 \%$ of patients were newly diagnosed. Most of the patients who had been diagnosed with epilepsy previously had received AED treatment prior to hospital admission (54 out of 61 patients). However, 38 (70.4\%) out of 54 patients reported irregular treatment. Majority of the of the 165 patients $(97.0 \%)$, reported having active epilepsy (seizure free $<1$ year) (10). Previous studies have shown that medication compliance is poor in this region. One study reported that $87.5 \%$ of patients were not taking regular treatment (1). The factors that may contribute to non-compliance include: patients' perception of the importance of the medication or lack of regular doctor's appointments (13). Furthermore, many patients turn to traditional Tibetan treatment in the Tibet Autonomous Region (2). A survey on the attitudes toward epilepsy among the general population in Ganzi, 2017, revealed that up to $67 \%$ of patients preferred traditional Tibetan medicine because they thought it would work (unpublished data). The current study revealed that $78.2 \%$ of patients had mono-therapy prescriptions when discharged from Ganzi People's Hospital. However, follow up was not done to ascertain their compliance to the medication. Medication reminders (14) and educational programmes (13) may increase compliance in these patients.

\section{Etiological Factors and Prevention of Parasite Infection}

Two previous population-based studies from the Tibet Autonomous Region did not conclusively describe the etiology of epilepsy in the patient populations studied. This may be due to the unavailability of EEG and CT/MRI data $(1,2)$. One study reported that seven and three patients developed epilepsy due to head trauma and neurocysticercosis, respectively (1). Another study (2) identified one patient with head trauma, one with neurocysticercosis, and 35 patients with seizures associated with heavy drinking or alcohol withdrawal. However, about $80 \%$ of patients in both studies have unknown etiologies. A strength of the current study is that most patients in our study underwent CT/MRI scans, hence, we were able to identify more etiological factors than previous study. The leading cause in this study was head trauma (20.6\%), followed by stroke (10.9\%), neurocysticercosis (7.9\%), brain hydatidosis $(6.7 \%)$, and tuberculous infection (5.5\%). Head trauma, stroke, cerebral infection are common causes for epilepsy. In the epidemiological survey of epilepsy in Rochester, Minnesota described the following etiological factors, such as cerebrovascular diseases (6\%), neurologic deficits from birth (5\%), trauma (5\%), and infection (4\%) (15). Head trauma, intracranial infection, and cerebrovascular diseases were the leading causes of epilepsy in a large population-based study in China in the 1980s (16). In comparison, the inpatient sample in Ganzi Tibetan area had parasite infection of the brain accounting for about $14.6 \%$ percent of all epilepsy patinets in this sample. This was higher than the age and gender matched control group. It was also significantly higher when compared with another etiology study in Chengdu (neurocysticercosis: 7.9 vs. 1.3\%, OR 6.271, 95\% CI 2.808-14.004; Brain hydatidosis: 6.7 vs. $0 \%$, OR $132.864,95 \%$ CI 7.788-2,266.400) (17). The adult of tapeworm live in the human intestine, and the intermediate hosts are pigs or yaks often found in this area. Humans often develop neurocysticercosis when they ingest raw meat containing cysts $(18,19)$. The adult of Echinococcus live in dogs or Tibetan foxes. Yaks serve as the intermediate hosts. Humans often get infected when they eat food contaminated with echinococcus eggs. Hydatidosis 
could occur in liver, lung or brain (20). Both cysticercosis and hydatidosis are endemic diseases in Ganzi. One study has shown that $22.5 \%$ of the study participants had positive serology positive for cysticercosis in Yajiang County, Ganzi. Half of the seropositive patients were noted to experience seizures (18). Approximately an eighth (12.9\%) of screened people were infected with hydatidosis in Shiqu County, Ganzi (21).

In the high pastures, many locals still live a traditionally pastoralism and semi-nomadism lifestyles, keeping dogs for herding animals. The domestic dog appears to be a key risk factor for both cystic and alveolar echinococcosis (20). Rates of echinococcosis infection in domestic dogs have been reported to be $5-15 \%$ in Tibetan area (22). Controlling the number of dogs and monthly praziquantel dog dosing programme is essential in preventing echinococcosis (20). Improvement of hygiene and promotion of hand-washing could also help in reducing infections (18).

Human taeniasis is acquired by eating uncooked or poorly cooked pork or beef infected with the larval form of the human taeniid tapeworms (19), there is a habitual consumption of undercooked beef and air-dried raw beef in this Tibetan community. Strategies to educate the locals on proper cooking of meat are important in the prevention of taeniasis (18).

Suprisely, the percentage of patients with unknown etiology was higher in the control group, suggesting that in-patients in Ganzi might have more identifiable seizure etiologies, such as infectious and structural changes. Hydatidosis is a critical and often fatal disease if left untreated (23). This study therefore proposes that all patients in this area with a new diagnosis of epilepsy should undergo a hydatidosis screen test.

The average altitude is 3,500 meters above sea level in Ganzi Tibetan Autonomous Prefecture. Excepted the two study in Tibet Autonomous Region which had been described above $(1,2)$, epidemiology of epilepsy in high altitude region was few (24), though there have been multiple case reports of seizures occurring in non-epileptic individuals and wellcontrolled epileptic patient at altitude (25-27). Still, the effect of altitude on the seizure threshold has not been studied in depth. This issue need to be explored more in future studies.

\section{Gender and Age}

Our study cohort comprised $58.2 \%$ male patients (male: female, 1.39:1). A door-to-door survey of six cities in China in 1987 regarding PWE reported a male-to-female ratio of 1.15:1 (16). An additional population-based survey in the Tibet Autonomous Region reported a male-to-female ratio of 1.73:1 (2). Our study may have a higher number of man than the number that is in the general population; however, our ratio is similar to those observed in previous studies that note a greater number of male patients than female patients.

Mean age of patients was $39.4 \pm 16.8$ years. The mean onset age was $34.5 \pm 18.0$. Our age group distribution was similar to that observed in previous population-based surveys in Tibetan area, with over half of the patients in the 15-44 years age group $(1,28)$. However, the predominant middle-age group in this study is unusual as compared to the bimodal age distribution reported in the literature $(15,28)$. This may be because many of them had infectious etiology, as the mean onset age of infectious etiology was $34.3 \pm 15.1$. Besides, Children $<14$ years of age were directed to the pediatrics department and hence most were not included in this study.

\section{Semiology}

In this cohort $28.5 \%$ of patients had generalized onset seizures and $68.5 \%$ of patients had focal onset seizures. Generalized tonicclonic seizures and focal to bilateral tonic-clonic seizures were the most commonly observed seizure type. This result is consistent with the findings of previous studies in the Tibet Autonomous Region $(1,2)$. However, the EEG application rate for epilepsy diagnosis was $30.9 \%$ in our study, which is significantly lower than the control group in Chengdu. This may compromise the accuracy of diagnosis, in particular for seizure semiology. Though the EEG rate in the current study is higher than that in previous research conducted in the Tibetan area $(1,2)$, it would be beneficial to have a much higher EEG rate in future studies.

\section{Study Limitations}

This is a hospital-based cohort and a retrospective study. Children younger than 14 years old, who were typically admitted to the Pediatric Department, were not included. This admission bias and our study results may not apply to the entire population in the Ganzi region. In addition, we found that $30.9 \%$ patients underwent EEG for epilepsy diagnosis; therefore, the accuracy of seizure semiology may be reduced. Nonetheless, the present study provides useful imformation for future studies and can guide the development of strategies for managing epilepsy in the Tibetan region.

\section{CONCLUSIONS}

This study suggests that the control of endemic infectious diseases in local regions, such as cysticercosis, and hydatidosis, is important for better prevention of epilepsy. In addition, education about seizures for local primary doctors and patients will enable better management of epilepsy in this population.

\section{DATA AVAILABILITY STATEMENT}

The raw data supporting the conclusions of this manuscript will be made available by the authors, without undue reservation, to any qualified researcher.

\section{AUTHOR CONTRIBUTIONS}

DZ designed this study. JiaC and XW carried out this study; those two authors collected data, analyzed data, and contributed equally to this study. JiaC, YH, YD, JieC, WF, and YL helped in data collecting. SL helped analyzed results. ZZ, JP, and JM helped in EEG data analysis, JiaC wrote the draft and XW revised the final version. 


\section{FUNDING}

This research was supported by funding from the International Bureau for Epilepsy 2017: The Education and Control Program of Epilepsy in Tibet Area (Item No. HX-H1711139).

\section{REFERENCES}

1. Zhao Y, Zhang Q, Tsering T, Sangwan, Hu X, Liu L, et al. Prevalence of convulsive epilepsy and health-related quality of life of the population with convulsive epilepsy in rural areas of Tibet Autonomous Region in China: an initial survey. Epilepsy Behav. (2008) 12:373-81. doi: 10.1016/j.yebeh.2007.10.012

2. Zhao Y-H, Zhang Q, Long N, Yang C, Hong J, Mu L, et al. Prevalence of epilepsy and alcohol-related risk in Zayul County, Tibet Autonomous Region in China: an initial survey. Epilepsy Behav. (2010) 19:635-8. doi: 10.1016/j.yebeh.2010.09.025

3. Government of Ganzi. Brief introduction of Ganzi. China Ganzi Portal (2015). Available online at: http://www.gzz.gov.cn/10000/10001/10003/ 10007/10000249.shtml (Accessed December 6, 2017).

4. Fisher RS, Acevedo C, Arzimanoglou A, Bogacz A, Cross JH, Elger CE, et al. ILAE official report: a practical clinical definition of epilepsy. Epilepsia (2014) 55:475-82. doi: 10.1111/epi.12550

5. Fisher RS, Boas WVE, Blume W, Elger C, Genton P, Lee P, et al. Epileptic seizures and epilepsy: definitions proposed by the International League Against Epilepsy (ILAE) and the International Bureau for Epilepsy (IBE). Epilepsia (2005) 46:470-2. doi: 10.1111/j.0013-9580.2005.66104.x

6. Trinka E, Cock H, Hesdorffer D, Rossetti AO, Scheffer IE, Shinnar S, et al. A definition and classification of status Epilepticus-Report of the ILAE task force on classification of status Epilepticus. Epilepsia (2015) 56:1515-23. doi: 10.1111/epi.13121

7. Scheffer IE, Berkovic S, Capovilla G, Connolly MB, French J, Guilhoto L, et al. ILAE classification of the Epilepsies: position paper of the ILAE Commission for Classification and Terminology. Epilepsia (2017) 58:512-21. doi: 10.1111/epi.13709

8. Shorvon SD. The etiologic classification of epilepsy. Epilepsia (2011) 52:10527. doi: 10.1111/j.1528-1167.2011.03041.x

9. Fisher RS, Cross JH, French JA, Higurashi N, Hirsch E, Jansen FE, et al. Operational classification of seizure types by the International League Against Epilepsy: position paper of the ILAE Commission for Classification. Epilepsia (2017) 58:522-30. doi: 10.1111/epi.13670

10. Thurman DJ, Beghi E, Begley CE, Berg AT, Buchhalter JR, Ding D, et al. Standards for epidemiologic studies and surveillance of epilepsy. Epilepsia (2011) 52:2-26. doi: 10.1111/j.1528-1167.2011.03121.x

11. Logroscino G, Hesdorffer DC, Cascino G, Annegers JF, Hauser WA. Shortterm mortality after a first episode of status Epilepticus. Epilepsia (1997) 38:1344-9. doi: 10.1111/j.1528-1157.1997.tb00073.x

12. Logroscino G, Hesdorffer DC, Cascino G, Hauser WA, Coeytaux A, Galobardes B, et al. Mortality after a first episode of status Epilepticus in the United States and Europe. Epilepsia (2005) 46:46-8. doi: 10.1111/j.1528-1167.2005.00409.x

13. Buck D, Jacoby A, Baker GA, Chadwick DW. Factors influencing compliance with antiepileptic drug regimes. Seizure (1997) 6:87-93. doi: 10.1016/S1059-1311(97)80060-X

14. Paschal AM, Rush SE, Sadler T. Factors associated with medication adherence in patients with epilepsy and recommendations for improvement. Epilepsy Behav. (2014) 31:346-50. doi: 10.1016/j.yebeh.2013.10.002

15. Hauser WA, Annegers JF, Kurland LT. Prevalence of epilepsy in rochester, minnesota: 1940-80. Epilepsia (1991) 32:429-45. doi: 10.1111/j.1528-1157.1991.tb04675.x

\section{ACKNOWLEDGMENTS}

We thank all doctors in the Neurology Department of Ganzi People's Hospital for their hard work in the world's highest plateaus known as the roof of the world.

16. Li S-C, Schoenberg BS, Wang C-C, Cheng X-M, Zhou S-S, Bolis CL. Epidemiology of epilepsy in urban areas of the People's Republic of China. Epilepsia (1985) 26:391-4. doi: 10.1111/j.1528-1157.1985.tb05 669.x

17. Si Y, Liu L, Hu J, Mu J, Fang J-J, An D-M, et al. Etiologic features of newly diagnosed epilepsy: hospital-based study of 892 consecutive patients in West China. Seizure (2012) 21:40-4. doi: 10.1016/j.seizure.2011. 09.008

18. Li T, Craig PS, Ito A, Chen X, Qiu D, Qiu J, et al. Taeniasis/cysticercosis in a Tibetan population in Sichuan Province, China. Acta Tropica (2006) 100:223-31. doi: 10.1016/j.actatropica.2006.11.003

19. Garcia HH, Moro PL, Schantz PM. Zoonotic helminth infections of humans: echinococcosis, cysticercosis and fascioliasis. Curr Opin Infect Dis. (2007) 20:489-94. doi: 10.1097/QCO.0b013e3282a95e39

20. Craig PS, McManus DP, Lightowlers MW, Chabalgoity JA, Garcia HH, Gavidia CM, et al. Prevention and control of cystic echinococcosis. Lancet Infect Dis. (2007) 7:385-94. doi: 10.1016/S1473-3099(07)70134-2

21. Tiaoying L, Jiamin Q, Wen Y, Craig PS, Xingwang C, Ning X, et al. Echinococcosis in Tibetan populations, western Sichuan Province, China. Emerg Infect Dis. (2005) 11:1866-73. doi: 10.3201/eid1112.050079

22. He J, Qiu J, Liu F, Chen X, Liu D, Chen W, et al. Epidemiological survey on hydatidosis in Tibetan region of western Sichuan. II. Infection situation among domestic and wild animals. Chin J Zoonoses (2000) 16:62-5. doi: 10.3969/j.issn.1002-2694.2000.05.019

23. Craig PS, Budke CM, Schantz PM, LI T, Qiu J, Yang Y, et al. Human echinococcosis: a neglected disease? Trop Med Health (2007) 35:283-92. doi: 10.2149/tmh.35.283

24. Mieske K, Flaherty G, O’Brien T. Journeys to high altitude-risks and recommendations for travelers with preexisting medical conditions. J Travel Med. (2010) 17:48-62. doi: 10.1111/j.1708-8305.2009.00369.x

25. Daleau P, Morgado DC, Iriarte CA, Desbiens R. New epilepsy seizure at high altitude without signs of acute mountain sickness or high altitude cerebral edema. High Alt Med Biol. (2006) 7:81-3. doi: 10.1089/ham.2006.7.81

26. Basnyat B. Seizures at high altitude in a patient on antiseizure medications. Wilderness Environ Med. (2001) 12:153-4. doi: 10.1580/ 1080-6032(2001)012[0153:LTTE]2.0.CO;2

27. Kuepper T, Classen J. Single grand mal seizures provoked by altitude? J Travel Med. (2002) 9:94-6. doi: 10.2310/7060.2002.21498

28. Wang WZ, Wu JZ, Ma GY, Dai XY, Yang B, Wang TP, et al. Efficacy assessment of phenobarbital in epilepsy: a large communitybased intervention trial in rural China. Lancet Neurol. (2006) 5:46-52. doi: 10.1016/S1474-4422(05)70254-4

Conflict of Interest Statement: The authors declare that the research was conducted in the absence of any commercial or financial relationships that could be construed as a potential conflict of interest.

Copyright (C) 2018 Chen, Wu, He, Li, Deng, Chen, Fang, Zeren, Peng, Li, Mu and Zhou. This is an open-access article distributed under the terms of the Creative Commons Attribution License (CC BY). The use, distribution or reproduction in other forums is permitted, provided the original author(s) and the copyright owner(s) are credited and that the original publication in this journal is cited, in accordance with accepted academic practice. No use, distribution or reproduction is permitted which does not comply with these terms. 